\title{
Vehicle Routing Problem for Electric Bus Energy Consumption and Planning
}

\author{
Wiroj Taweepworadej ${ }^{1}$ and Panhathai Buasri ${ }^{2}$
}

\begin{abstract}
Electric vehicle driving distance is one important factor for energy consumption management. In this paper, the vehicle routing problem was applied to find the shortest circular path distance and also the best location for building the storage hub and electric vehicle charging station. The energy consumption estimations of electric buses on the shortest circular path were calculated and compared for electric bus with different energy consumption rates. The best delivery bus routes scheduling was proposed to minimize the number of battery recharge. For the giving points, the best circular travelling route is $71.16 \mathrm{~km}$ and energy consumption per loop of 92.51-128.09 kWh. In addition, choosing the right storage and electric recharging location can reduce the number of battery recharge and lower the battery overhead per trip down $16.66 \%$.
\end{abstract}

Keywords-Energy Consumption Estimation, Energy Consumption Management, Plug-in Electric Vehicle, Vehicle Routing Problem.

\section{INTRODUCTION}

C ONSIDERED as a potential environmental friendly alternative, plug-in electric vehicle (PEV) is one of the promising solutions to reduce the use of fossil fuels and greenhouse gas emissions. PEV is achieving a wide interest from industries. Several types of PEVs, such as passenger vehicle, truck, and bus, have been developed for decades. Electric bus as local public transportation as fixed or flexible routes as school bus, metropolitan transportation bus shows good performance and energy saving on driving tests and it has lower investment cost per person and less cost on maintenance than private vehicle.

PEV has limited driving range in electric operation. The onboard battery needs to be recharge to have sufficient energy to cover the desired driving distance. However, it is difficult to charge electric bus on road due to the lack of fast charging infrastructure and possible long charging time and waiting time accounted for more than 4 hours per charge. Electric bus prefers to be used during the day and charged at night when it is parked to avoid peak load period of electrical grid [1-3]. The vehicle routing problem (VRP) is an efficient method to find the best solution for the shortest circular path [4]. For electric bus with multiple stops, the shortest circular path is

Wiroj Taweepworadej ${ }^{1}$ is with Khon Kaen University, Thailand 40002 Panhathai Buasri ${ }^{2}$ is with khon Kaen University, Thailand importance for effectively managing the battery energy due to driving distance limitation. The PEV charging station location issue is a very interesting topic area such as the station planning model, new charging infrastructure and also the station location. Most station location problems are based on existing optimization solution including the classic VRP [5].

In this paper, we aim to deal with the issue of strategic planning for building electric vehicle charging station at the storage hub related to the circular shortest distance calculated by the set of fixed routes based on electric bus energy consumption. The problem formulation allows a simple implementation of vehicle routing problem algorithm to search for an optimal route. The charging and saving energies are compared among three different buses for the proposed route. In addition, the delivery travelling routes are scheduled in order to minimize the number of batter recharge and reduce costs.

\section{BACKGROUND}

\section{A. Vehicle Routing Problem}

A vehicle starts driving from a starting and terminal point A then it passes every point at least once and then returns to point A, considered as one circular loop. The Vehicle Routing Problem may be formally stated as follows:

1. Given a set of $n$ "bus stops" $P_{i}(i=1,2 \ldots n)$ to which deliveries are made from point $\mathrm{P}_{0}$, called the "starting and terminal point".

2. A "Distance Matrix" $[D]=\left[\mathrm{d}_{\mathrm{ij}}\right]$ is given which specifies the distance $d_{i j}=d_{j i}$ between every pair of points $(i, j=0$, $\ldots, n)$.

3. If $\mathrm{x}_{\mathrm{ij}}=\mathrm{x}_{\mathrm{ji}}=1$ is interpreted to mean that points $\mathrm{P}_{\mathrm{i}}$ and $\mathrm{P}_{\mathrm{j}}$ are paired $(\mathrm{i}, \mathrm{j}=0, \ldots, \mathrm{n})$ and if $\mathrm{x}_{\mathrm{ij}}=\mathrm{x}_{\mathrm{ji}}=0$ means that the points are not paired, one obtains the condition

$$
\sum_{j=0}^{n} x_{i j} \geq 1 \text { for } \mathrm{i}=1, \ldots, \mathrm{n}
$$

(1)

since every point $P_{i}$ is either connected with $P_{0}$ or at most one other point $P_{j}$. Furthermore, by definition, $x_{i i}=0$ for every $\mathrm{i}=0, \ldots, \mathrm{n}$.

4. The problem is to find those values of $x_{i j}$ which make the total distance minimum. 


$$
D=\sum_{i, j=0}^{n} d_{i j} x_{i j}
$$

The linear programming formulation can be applied to obtain an optimal solution.

\section{B. Energy Consumption of Electric Bus}

Besides taking large amount of passengers than private vehicle, electric bus has lower maintenance cost per passengers. Passenger can use electric bus with and without knowledge about electric motor operation and power conversion system leading to wider acceptance technology to general public. Electric bus has been developed for public transportation such as school bus, airport bus, and tour bus. For electric bus, battery storage is the main power source to propel the wheels with in limited speed and driving distance. Electricity is supplied or recharged the battery for longer distance. AC electricity from electrical grid is converted to DC power to recharge the battery at charging station. Fast charging and slow charging levels are introduced in several countries. Fast charging delivered high current in short amount of time than slow charging. The energy consumption of a vehicle depends on electric motor characteristics on any driving speed, road conditions, driving styles, and maximum distance per charge. The energy demand at a constant vehicle speed can be written as (3).

$$
E=\left(\frac{1}{2} \rho A C_{d} v^{3}+\mu m a+\frac{1}{2} m v^{2}+m g \sin \theta\right) \cdot \Delta t
$$

Where $\rho$ is air density

A is frontal area

$\mathrm{C}_{\mathrm{d}}$ is coefficient of the vehicle

Electric bus can be travel on repeated route per day and recharge during each trip so that less number of buses to buy or use. Number of recharging times $(\mathrm{X})$ can be calculated fir total driving distance (D) and distance per trip(d) as,

$$
X=\frac{D}{d}
$$

Rate of electricity consumption is given by standard driving test such as HWFET, UDDS, etc. Fully charging battery can support power up to certain maximum distance $\left(D_{\max }\right)$. Battery has longer life cycle if it recharged from minimum allowance level. Normally battery can be used for $60-80 \%$ of its capacity.

\section{RESUltS AND DisCUSSIONS}

The algorithm was tested on real world data with 7 points (A to G). One point will be selected as the starting and terminal point while the others are bus stops which goods must be delivered. Three different types of electric buses with the energy consumption rate of $1.3,1.5,1.8 \mathrm{kWh} / \mathrm{km}$ were calculated and compared. All selected vehicle has a distance

\begin{tabular}{|c|c|c|c|c|c|c|c|}
\hline \multirow{2}{*}{$\begin{array}{l}\text { Distance } \\
\text { From: }\end{array}$} & \multicolumn{3}{|c|}{ To: } & \multirow[b]{2}{*}{ D } & \multirow[b]{2}{*}{$E$} & \multirow[b]{2}{*}{$\mathrm{F}$} & \multirow[b]{2}{*}{$\mathrm{G}$} \\
\hline & Point & B & $\mathrm{C}$ & & & & \\
\hline & $\mathrm{A}$ & 2.26 & 5.48 & & & & \\
\hline & $B$ & & 4.5 & 6.12 & & & \\
\hline & $\mathrm{C}$ & & & 3.86 & 10.3 & & \\
\hline & D & & & & 2.26 & 2.26 & 22.2 \\
\hline & $E$ & & & & & 6.76 & \\
\hline & $F$ & & & & & & 25.1 \\
\hline
\end{tabular}
capacity of $250 \mathrm{~km}$. The destination and distance between each point are presented in Fig. 1. (a)

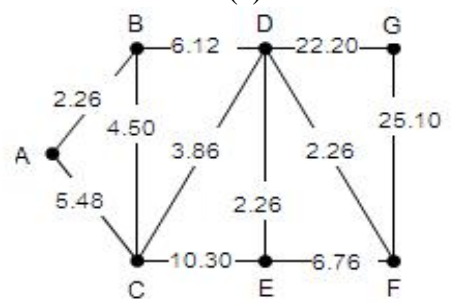

(b)

Fig. 1 Destination and distance. (a) Distance table. (b) Distance map.

The results of the vehicle routing problem algorithm can be presented in Fig. 2.

Distance
From:
\begin{tabular}{|c|c|c|c|c|c|c|c|} 
Point & A & B & C & D & E & F & G \\
\hline A & & 2.26 & $5.48^{*}$ & & & & \\
\hline B & $2.26^{*}$ & & & 6.12 & & & \\
\hline C & 5.48 & & & $3.86^{*}$ & & & \\
\hline D & & $6.12^{*}$ & 3.86 & & 2.26 & 2.26 & 22.2 \\
\hline E & & & & 2.26 & & & \\
\hline F & & & 2.26 & & & \\
\hline G & & & & 22.2 & & & \\
\hline
\end{tabular}
* an alternative path

(a)

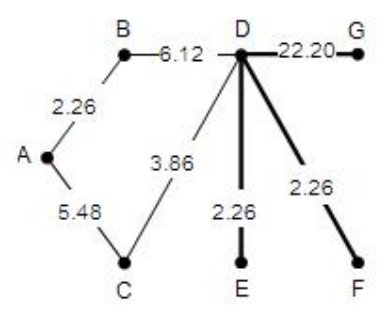

(b)

Fig. 2 Vehicle routing problem algorithm findings. (a) Shortest circular path distance table. (b) Shortest circular path distance map.

To the shortest circular graph, point $\mathrm{D}$ has the highest degree of pairing condition between every pair of point $i, j$ (for $\mathrm{i}, \mathrm{j}=0, \ldots, \mathrm{n}$ ). This makes point $\mathrm{D}$ is the best location to implement an electric vehicle charging station. The shortest circular path is $71.16 \mathrm{~km}$ for one roundtrip by travelling through 4 closed loops as follows: D-B-A-C-D (or D-C-A-BD), D-E-D, D-F-D and D-G-D. To finish the travelling cycle, the bus may travel pass all 4 loops in any orders. This will increase flexibility for driver to perform his task to increase the saving of energy consumption.

The energy consumption and electricity cost of three electric buses are presented in Table I while the gasoline consumption and cost of the same type of ICE buses are also presented in Table II. 
TABLE I

THE ENERGY CONSUMPTION AND ELECTRICITY COST

\begin{tabular}{|c|c|c|c|}
\hline Type & $\begin{array}{c}\text { Energy } \\
\text { Consumption rate } \\
(\mathrm{kWh} / \mathrm{km})\end{array}$ & $\begin{array}{c}\text { Energy } \\
\text { Consumption } \\
\text { per R/T }(\mathrm{kWh})\end{array}$ & $\begin{array}{c}\text { Electricity Cost } \\
\text { (dollars) }\end{array}$ \\
\hline $\mathrm{A}$ & 1.3 & 92.51 & 7.12 \\
\hline $\mathrm{B}$ & 1.5 & 106.74 & 8.22 \\
\hline $\mathrm{C}$ & 1.8 & 128.09 & 9.86 \\
\hline
\end{tabular}

TABLE II

THE GASOLINE CONSUMPTION AND COST

\begin{tabular}{|c|c|c|}
\hline Type & Gasoline Consumption & Gasoline Cost (dollars) \\
\hline A & 2.75 & 8.25 \\
\hline B & 3.17 & 9.51 \\
\hline C & 3.80 & 11.40 \\
\hline
\end{tabular}

The amount of energy consumption for three different types of PEV are 92.51, 106.74, $128.09 \mathrm{kWh}$ per one roundtrip. The electricity charging period for PEV is 4-6 hours during the evening and night, from 21h 00 until 06h 00 in the morning. For off-peak, electricity price is 7.7 cents/kwh [3], that makes electricity cost for each vehicle types at least 1 dollar lower comparing to gasoline cost of an equivalent energy consumed by the ICE bus (2.75, 3.17, 3.8 gallons) [7].

The proposed travelling circular path model was simulated in order to optimize the number of battery recharge. The distance of each travelling path is shown in Table III and the simulation results are shown in Table IV. By using the shortest circular path, the number of trips per one time charging is 3 and the total distance per day is $213.48 \mathrm{~km}$. Choosing $\mathrm{D}$ as the storage hub, the simulation confirms that the number of trips will be increased to be 10 for the first three time charging (3.33 per one time charging) and to be 7 for every the following two time charging (3.50 per one time charging). This will reduce the battery cost per trip down 16.66\% for using the Lithium Iron Phosphate battery.

TABLE III

The Distance OF EACH TRAVELLING PATH

\begin{tabular}{|l|c|}
\hline \multicolumn{1}{|c|}{ Paths } & Distance \\
\hline 1: D-B-A-C-D & 17.72 \\
\hline 2: D-E-D & 4.52 \\
\hline 3: D-F-D & 4.52 \\
\hline 4: D-G-D & 44.40 \\
\hline one circular loop & 71.16 \\
\hline
\end{tabular}

TABLE IV

THE SiMULATION RESUltS FOR EACH RECHARGE

\begin{tabular}{|c|l|l|c|}
\hline $\begin{array}{c}\text { Recharge } \\
\text { no. }\end{array}$ & \multicolumn{1}{|c|}{ Travelling performed } & $\begin{array}{c}\text { Total } \\
\text { distance }\end{array}$ & $\begin{array}{c}\text { Total } \\
\text { loops }\end{array}$ \\
\hline 1 & 3 circular loops; path 1, 2, 3 & 240.24 & 3 \\
\hline 2 & path 4; 2 circular loops; path 1, 4 & 248.84 & 6 \\
\hline 3 & path 2, 3; 3 circular loops; path 1, 2, 3 & 249.28 & 10 \\
\hline 4 & path 4; 2 circular loops; path 1, 4 & 248.84 & 13 \\
\hline 5 & path 2, 3; 3 circular loops; path 1, 2, 3 & 249.28 & 17 \\
\hline
\end{tabular}

\section{CONCLUSION}

The vehicle routing problem algorithm for solving shortest circular path problem for an electric bus routing with 7 stop points is presented. The results show that method is effective and simple to find the bus circular travelling route of the minimum total distance under limited range of electric vehicle. The energy demand for charging is low and cheap compared to ICE vehicle demand for equivalent energy. The cost of one trip charging electricity from electrical grid is about 7.12-9.86 dollars for distance of $71.16 \mathrm{~km}$. Different average speeds of each route can have different results of shortest distance and energy saving of EV bus. The proposed method also recommends the best location for constructing the storage hub and electric recharging center, as a consequence, the number of travelling trips will be increased and the battery cost is reduced.

\section{ACKNOWLEDGMENT}

Author would like to thank Khon Kaen University for partial financial support.

\section{REFERENCES}

[1] Michael Metz, Christian Doetsch, Electric vehicles as flexible loads- A simulation approach using empirical mobility data, Energy, 48, pp.369374, 2012.

http://dx.doi.org/10.1016/j.energy.2012.04.014

[2] V. Wynen, F. S. Boureima, J. Matheys, P. Van Den Bossche, J. Van Mierlo, Developing applicable driving for retrofitted plug-in hybrid electric vehicle(PHEVs): environmental impact assessment,World Electric Vehicle Journal, Vol.3, pp. 1-13,2009.

[3] S. Negarestani, A.R. Ghahnavieh, A.S. Mobarakeh, A study of the reliability of various types of the electric vehicles, IEEE int. Electric Vehicle Conference, pp.1-6, 2012.

[4] J. Christopher Beck, Patrick Prosser, Evgeny Selensky, "Vehicle Routing and Job Shop Scheduling: What the Difference?”, in Proc. the 13th International Conference on Artificial Intelligence Planning and Scheduling, 2003.

[5] Worley, O., Klabjan, D. and Sweda, T., Simultaneous Vehicle Routing and Charging Station Siting for Commercial Electric Vehicles, IEEE International Electric Vehicle Conference, Greenville, NC, 2012. http://dx.doi.org/10.1109/ievc.2012.6183279

[6] Greg Davis, BYD Electric bus, available at http://www.byd.com/na/ auto/ElectricBus.html on October 2014.

[7] Tilde Herrera, Electric buses plug in to US Market with new models, more bucks, available at http://www.greenbiz.com /blog/ 2011/10/25/electric-buses-plug-into-us-markets-new-models-more-bucks on October 2014. 